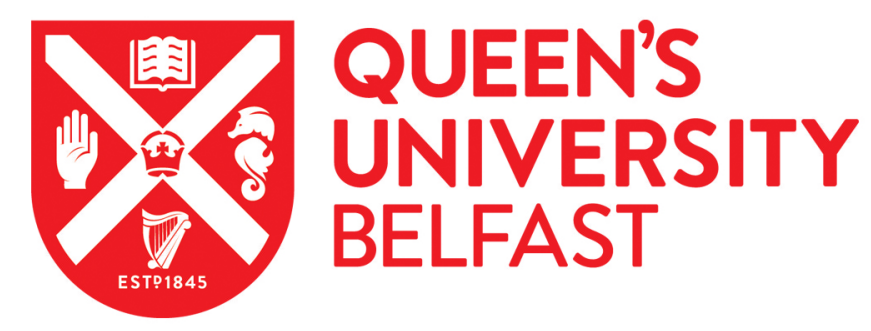

\title{
Enhanced Extraction of Phenol from Model Oils Using lonic Liquids Elucidated with Neutron Diffraction
}

Turner, A. H., Byrne, E. L., Pereira, T., \& Holbrey, J. D. (2020). Enhanced Extraction of Phenol from Model Oils Using lonic Liquids Elucidated with Neutron Diffraction. Physical Chemistry Chemical Physics (PCCP), 22(18), 10219-20226. https://doi.org/10.1039/D0CP01013H

Published in:

Physical Chemistry Chemical Physics (PCCP)

Document Version:

Peer reviewed version

Queen's University Belfast - Research Portal:

Link to publication record in Queen's University Belfast Research Portal

Publisher rights

Copyright 2020 RSC. This work is made available online in accordance with the publisher's policies. Please refer to any applicable terms of use of the publisher.

\section{General rights}

Copyright for the publications made accessible via the Queen's University Belfast Research Portal is retained by the author(s) and / or other copyright owners and it is a condition of accessing these publications that users recognise and abide by the legal requirements associated with these rights.

Take down policy

The Research Portal is Queen's institutional repository that provides access to Queen's research output. Every effort has been made to ensure that content in the Research Portal does not infringe any person's rights, or applicable UK laws. If you discover content in the Research Portal that you believe breaches copyright or violates any law, please contact openaccess@qub.ac.uk. 


\title{
Enhanced Extraction of Phenol from Model Oils Using Ionic Liquids Elucidated with Neutron Diffraction ${ }^{\dagger}$
}

\author{
Adam H. Turner, ${ }^{, a, b}$ Emily Byrne, ${ }^{a}$ Thaise Pereira, ${ }^{a}$ and John D. Holbrey ${ }^{a}$ \\ Physical Chemistry Chemical Physics, paper accepted for publication 7 April 2020 - CP-ART-02-2020-001013
}

\begin{abstract}
Aromatic cation ionic liquids (ILs) based on alkylpyridiniums are shown to be good phenol extractants from model oils (hexane/toluene). ILs with hard basic anions are found to have best extraction efficiency consistent with tetraalkylammonium salts $\left(\left[\mathrm{NR}_{4}\right] \mathrm{X}\right)$. Key extraction interactions were analysed using small angle neutron diffraction. Trifluoromethanesulfonate ([OTf $]^{-}$or triflate) anions provide the synergistic effects of reduced cation-phenol centre of mass (COM) distances and increased hydrogen bonding that are linked to the improved extraction efficiency. Increases in cation electron density (methyl-pyridinium $\left([\mathrm{Me}-\mathrm{Py}]^{+}\right.$) vs methyl-picolinium $\left([\mathrm{Me}-3-\mathrm{Pic}]^{+}\right)$) also reduce cation-phenol COM interaction lengths consistent with small increases in extraction efficiency for the same ionic liquids.
\end{abstract}

\section{Introduction}

As intermediates for the manufacture of plastics, polymers, paper pulping, pesticides, drugs such as aspirin, etc. phenols are pervasive in the environment. This pervasiveness coupled with their substantial threat to human health ${ }^{1}$ has made them a target for EU (Council Directive 98/83/EC) and US ${ }^{2}$ legislatures. The EU limits phenol concentrations to less than $0.5 \mu \mathrm{g} \cdot \mathrm{L}^{-1}$ in drinking water. Phenolic compounds can enter the environment in myriad ways such as; liquification of coal tars, ${ }^{3}$ fuel processing, $\frac{4}{4}$ and oxidation of cumene. $\frac{5}{5}$

Current industrial methods to separate phenols from oils makes use of aqueous alkaline solutions $(\mathrm{NaOH})$ from which the phenol is recovered by acidifying with mineral acids $\left(\mathrm{H}_{2} \mathrm{SO}_{4}\right)$, requiring the use of stoichiometric quantities of strong acids and bases and subsequently generating considerable amounts of phenolcontaminated waste water. To address some of these environmental problems, alternative phenol remediation methods have been studied including chemical oxidation, biodegradation, absorption, and solvent extraction. 6

Solvent extraction typically involves use of volatile, toxic, and flammable organic solvents such as methyl isobutyl ketone (MIBK) ${ }^{7}$ As an alternative to volatile organic solvents, ionic liquids ${ }^{8[9}$ have been studied for extraction processes, including the use of alkyl-imidazolium ionic liquids for extraction of phenols from water ${ }^{10}-12$ and model oils. $\frac{13 \mid 14}{12}$ Phenol could be recovered from the ionic liquid by sublimation, taking advantage of the general vanishingly low volatility of ionic liquids. An allied group of solvents, deep eutectic solvents (DES) have also been utilised for extraction of phenol from model oils. ${ }^{15} \cdot 17$ Marsh and co-workers first demonstrated that induced formation of a DES between phenol and choline chloride or other tetraalkylammonium salts could be used to extract phenols from oils with $\sim 90 \%$ extraction. $\frac{15}{15}$ Stripping with dialkylethers to recover phenols from the DES was demonstrated. Ionic liquids containing N-alkylpyridinium cations have been shown to be somewhat biodegradable ${ }^{18}$ and are thus viable candidates for industrially utilised extractions.

The ability of an ionic liquid or DES to interact with phenol is dependent on the formation of dipoledipole, ion-dipole, dispersion, van der Waals and hydrogen bond interactions. Thus it is necessary to understand how these phenol-ionic liquid mixtures interact. We have previously investigated the interactions and

${ }^{a}$ The QUILL Research Centre, School of Chemistry and Chemical Engineering, Queen's University Belfast, Belfast BT9 5AG, UK. Tel: +44 (0) 28 9097 5479; E-mail: j.holbrey@qub.ac.uk

${ }^{b}$ Department of Chemistry, Ateneo de Manila University, Quezon City 1108, Philippines. Tel: +63 2426 6001; E-mail: aturner@ateneo.edu

$\dagger$ Electronic Supplementary Information (ESI) available: synthesis and extraction experimental procedures, reference potentials, structure factors, RDFs, pRDFs, hydrogen bonding details, simulation snapshots, clusters, chains and triangles analysis. See DOI: 00.0000/00000000. 
association of phenol with $\mathrm{N}$-methylpyridinium bis\{(trifluoromethyl)sulphonyl\}imide using neutron diffraction, 19 revealing that $\pi$ - $\pi$ co-facial association between pyridinium cations and phenol rings was the primary interaction motif, and is accompanied by weak, diffuse hydrogen-bonding from the donor hydroxyl moiety of the phenol to $\left[\mathrm{NTf}_{2}\right]^{-}$anions.

Extractions of phenol from model oils using $N$-alkylpyridinium and ammonium salts and ionic liquids have been performed with hard basic anions giving the best extraction efficiencies. The impact of how introducing a [OTf] ${ }^{-}$anion (improved hydrogen bonds) and more electron rich [Me-3-Pic] ${ }^{+}$(improved $\pi$ $\pi$ interactions) cation on the association modes with phenol in 2:1 ionic liquid:phenol liquid mixtures are investigated across each cation and anion pair (see Table $\mathrm{S}^{\dagger}$ ) with the four ionic liquids: $N$-methylpyridinium bis $\left\{\right.$ (trifluoromethyl)sulphonyl\}imide [Me-Py] $\left[\mathrm{NTf}_{2}\right], N$-methylpyridinium trifluoromethylsulphonate ([MePy][OTf]), $N$-methyl-3-picolinium trifluoromethylsulphonate ([Me-3-Pic][OTf]), and $N$-methyl-3-picolinium bis $\left\{\right.$ (trifluoromethyl)sulphonyl\}imide ([Me-3-Pic] $\left[\mathrm{NTf}_{2}\right]$ ) as shown in Figure 1 .

\section{Methods ${ }^{\dagger}$}

\subsection{Phenol extraction screening}

Extraction experiments followed the methods described in the literature. ${ }^{[15}$ Stock solutions containing phenol $(0.1 \mathrm{M})$ and dodecane $(0.01 \mathrm{M})$ in hexane or toluene were prepared. Typically, a $20 \mathrm{~cm}^{3}$ aliquot of model oil (containing phenol) was added to a glass tube equipped with a magnetic follower and immersed in an oil bath held at $30^{\circ} \mathrm{C}$. An accurately measured mass of extractant $(2 \mathrm{mmol}$, corresponding to 1:1 molar ratio to the phenol content) was added. The tube was sealed and the mixture stirred vigorously for $30 \mathrm{~min}$. and then allowed to settle for $30 \mathrm{~min}$. The upper oil phase was then sampled and analysed by GC $\left(\mathrm{ESI}^{\dagger}\right)$.

Pyridine, pyridine- $d_{5}$ (99.5 atom \% D), 3-picoline, methyl (trifluoromethane)sulphonate $\}$, methyl (trifluoromethane)sulphonate $\}-d_{3}$ (99 atom \% D), phenol, phenol- $d_{6}$ (99 atom \% D), dimethylsulphoxide- $d_{6}$ (99.9 atom \% D) were purchased from Sigma-Aldrich. 3-picoline- $d_{7}$ (98 atom \% D) was purchased from $\mathrm{CDN}$ Isotopes, Canada. Li[NTf $\left.{ }_{2}\right]$ was purchased from $3 \mathrm{M}$. All reagents were used as received without further purification

Salts were synthesised by alkylation of either pyridine or picoline followed by anion metathesis in the case of the $\left[\mathrm{NTf}_{2}\right]^{-}$ionic liquids. Representative syntheses are based on previously reported methods ${ }^{19}$ and are presented in the ESI ${ }^{\dagger}$.

\subsection{Neutron scattering experiments}

Small angle neutron scattering data were collected using the SANDALS spectrometer at the ISIS pulsed neutron and muon source in the Rutherford Appleton Laboratory, UK. A "null scattering" $\mathrm{Ti}_{0.68} \mathrm{Zr}_{0.32}$ flat plate cell each with internal geometries of $1 \times 35 \times 35 \mathrm{~mm}$ (wall thickness $=1 \mathrm{~mm}$ ) was used to collect sample data. Temperature was maintained at $333 \mathrm{~K}$ during the measurements using a Julabo FP50 recirculating heater. Instrument calibration and data normalisation measurements on each of the empty sample holders, the empty spectrometer, and a $3.1 \mathrm{~mm}$ thick vanadium standard sample.

GUDRUN $^{20}$ was used for data reduction to produce a differential scattering cross section for each experimental sample. The experimental sample densities and scattering levels were consistent with the actual isotopic compositions of the samples. Subtracting for single atom scattering using the calibration and background data afforded differential scattering cross sections. These corrected experimental data-sets were then analysed using the Empirical Potential Structure Refinement (EPSR) program. ${ }^{2122}$

The experimental total structure factors, $\mathrm{F}(Q)$, were extracted from the neutron scattering data for each of the isotopically distinct samples at each composition. These were used to build and refine EPSR derived three dimensional models of each liquid consistent with the experimental data. From the differences between the experimental and calculated structure factors in $Q$-space for each data-set, an empirical perturbation potential is determined. The simulation is iteratively driven towards agreement with the experimental data by combining the empirical and reference potentials. 

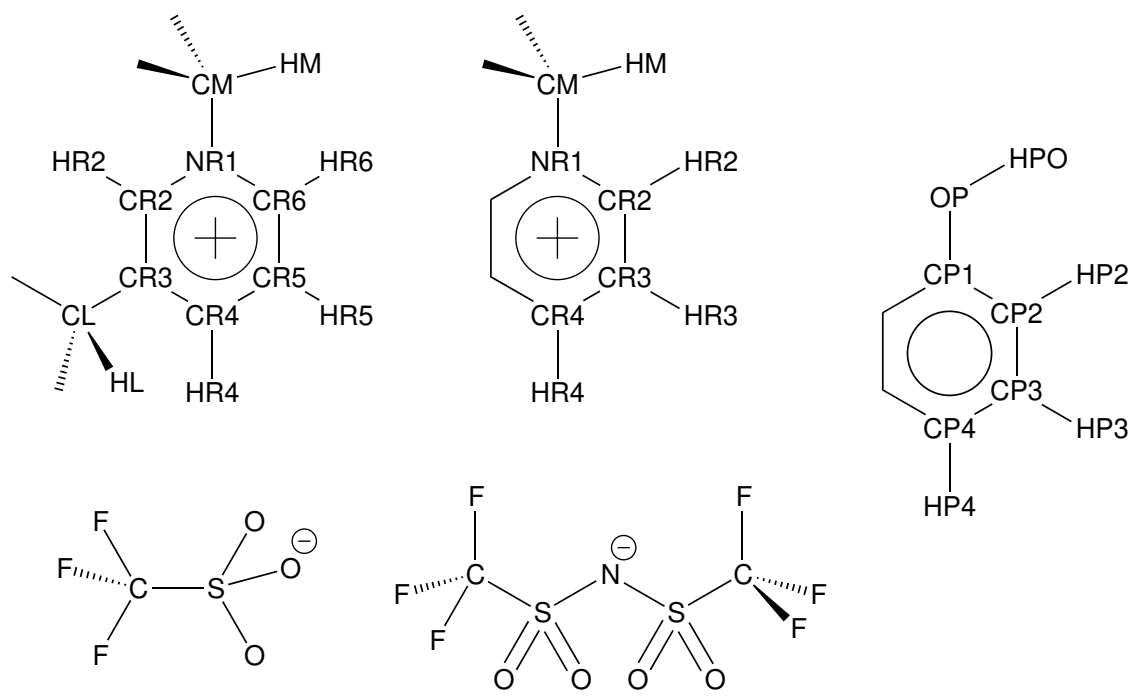

Fig. 1 Atom types assigned to the ionic liquid and phenol components used in the EPSR simulation of the neutron scattering data.

The EPSR calculations were performed using 500 ionic liquid pairs and 250 phenol molecules. The simulations were performed using cubic dimensions of $48.73 \AA$, $53.26 \AA, 47.86 \AA$, and $54.52 \AA$ for the mixtures of phenol with [Me-3-Pic][OTf], [Me-3-Pic][NTf ${ }_{2}$, [Me-Py][OTf] and [Me-Py] $\left[\mathrm{NTf}_{2}\right]$ respectively. EPSR models were refined against the full experimental data range $\left(Q=0.1-50 \AA^{-1}\right)$. Atom types for each system were defined based on their position in the molecular skeleton as shown in Figure 1, full rotational flexibility was enabled for the model. Reference potential parameters are given in the ESI in Table S2, ${ }^{\dagger}$ interatomic distance and angular constraints used to define the basic molecular geometries are summarised in Table S3. ${ }^{\dagger}$

Simulations were allowed to equilibrate for at least 5000 cycles before applying the empirical potential and then were equilibrated over ca. 30000 cycles before accumulating data. The total numeric density of the simulation box corresponded to the experimentally determined molecular densities of the fully protiated materials at $60{ }^{\circ} \mathrm{C}\left([\mathrm{Me}-3\right.$-Pic $][\mathrm{OTf}]=1.37 \mathrm{~g} \mathrm{~cm}^{-1}$, [Me-3-Pic][NTf $\left.{ }_{2}\right]=1.48 \mathrm{~g} \mathrm{~cm}^{-1}$, [Me-Py][OTf $]=$ $1.40 \mathrm{~g} \mathrm{~cm}^{-1}$, and [Me-Py] $\left[\mathrm{NTf}_{2}\right]=1.47 \mathrm{~g} \mathrm{~cm}^{-1}$ ). Centre of mass radial distribution functions (RDFs) were calculated using the SHARM routines with EPSR.

\section{Results and Discussion}

\subsection{Model Extraction}

Phenol extraction from hexane and toluene solutions as model oils was examined following the procedure described by Guo et al. $\frac{15}{15}$ Initially, a broad range of tetraalkylammonium halide salts $\left(\left[\mathrm{NR}_{4}\right] \mathrm{X}, \mathrm{R}=\mathrm{Me}\right.$, Et, $\mathrm{Pr}, \mathrm{Bu}$, and $\mathrm{X}=\mathrm{Cl}, \mathrm{Br}$, I) were screened as eutectic forming extraction agents to benchmark and compare with the literature (See Table S2, and Figs. S2 and S3, ESI ${ }^{\dagger}$ ). Some clear trends in extraction efficiencies with changes to the cation and anion components of the eutectic forming organic salts on phenol extraction are apparent. Hard, basic anions (supporting phenol-OH hydrogen bond donation to the anion as a primary association mode ${ }^{1923}$ ) significantly enhance extraction efficiency, especially from aromatic solvents such as toluene.

Fig. 2 Extraction efficiencies of four ionic liquids of phenol for the purification of a model oil (hexane, toluene). [Me3-Pic][OTf] (95\%, $63 \%)$, [Me-3-Pic][NTf ${ }_{2}$ ] (81\%, $\left.29 \%\right)$, [Me-Py][OTf] $(92 \%, 54 \%)$, and [Me-Py][NTf ${ }_{2}$ ] (77 \%, 25 $\%)$ 
Phenol extraction from hexane and toluene through DES formation with [Me-3-Pic][OTf], [Me-3-Pic] [NTf ${ }_{2}$, [Me-Py][OTf] and [Me-Py] $\left[\mathrm{NTf}_{2}\right]$ was examined to establish whether the projected changes in cation electron density $\left([\mathrm{Me}-3-\mathrm{Pic}]^{+}>[\mathrm{Me}-\mathrm{Py}]^{+}\right.$) and anion hydrogen bond basicity $\left([\mathrm{OTf}]^{-}>\left[\mathrm{NTf}_{2}\right]^{-}\right.$) would lead to extraction in line with predicted trends. Results of the experiments can be found in Figure 2 and show that the most activity was with the [OTf] ${ }^{-}$ionic liquids confirming the assumption that by increasing the net interaction of the ionic liquid, a better affinity for phenol in model oils could be achieved.

The $[\mathrm{OTf}]^{-}$ionic liquids have higher extraction activity than $\left[\mathrm{NTf}_{2}\right]^{-}$ionic liquids due to the harder anion, this effect is more pronounced for toluene systems due to the increase in other competitive interactions (such as aromatic ring $\pi-\pi$ stacking). Increasing the electron density of the cation, going from a pyridinium to picolinium cation causes a modest increase in extraction efficiency but this factor is less important than improving anion-phenol interactions. The rise in efficiency with increasing cation electron density is largely uncorrelated with changing cation-phenol COM interaction distances.

These extraction results are comparable with those of the $\mathrm{Cl}^{-}$and $\mathrm{Br}^{-}$tetraalkylammonium salts (ESI) and follow similar trends. Increased electron density on the cation, and smaller, harder anions improve extraction efficiency. The $\mathrm{Cl}^{-}$salts have the best extraction efficiency partially attributed to their strong basicity (higher than [OTf $]^{-}$anions). In both tetraalkylammonium and pyridinium systems, extraction efficiency is reduced when phenol is dissolved in toluene rather than hexane. They also compare well with results in the literature, Pang et al. ${ }^{24}$ was able to use choline chloride to extract $91 \%(\mathrm{~m} / \mathrm{m})$ of phenol from a toluene/phenol solution. Higher extraction percentage for the methyl-pyridinium versus the pyridinium (though marginal) is consistent with the behaviour of these types of ionic liquids in the extraction of dibenzothiophene from model oils. ${ }^{25}$ This is likely due to the electron donating ability of the methyl group improving cation-phenol interactions but not causing significant packing problems for the hydroxyl group of the phenol.

The interactions between phenol and the ionic liquid components in these mixtures were then investigated using small angle neutron diffraction to elucidate how the extraction efficiency is improved on change of anion and cation.

\subsection{Experimental neutron diffraction data and fits}

Experimental data was collected at $333 \mathrm{~K}$ on 2:1 IL:phenol mixtures with [Me-3-Pic][OTf], [Me-3-Pic] [NTf ${ }_{2}$, [Me-Py][OTf] and [Me-Py] $\left[\mathrm{NTf}_{2}\right]$. Data was modelled using EPSR, continuously refining against the experimental data obtained at each different composition. The results in Figure 3 show good agreement between experimental data and EPSR derived models.

Centre of mass radial distribution functions (RDFs - Figure 4) were calculated between the three components, cation, anion, and phenol using the EPSR model. The position of the first peak $\left(r_{\max }\right)$ in the RDFs is shown in Table 1. The RDFs show first shell correlations between components between 5-6 $\AA$ in each mixture with cations surrounded by anions and phenols, anions surrounded by cations and phenol and phenol surrounded by cations, anions and phenol as anticipated. The first cation-cation and anion-anion RDF peaks occur at distances $>6.5 \AA$ indicating that this is a second shell association and are present as broad, diffuse correlations will little fine structure. It is notable that the ionic liquids containing [OTf] ${ }^{-}$anions have sharper, more defined RDF peaks whereas those containing $\left[\mathrm{NTf}_{2}\right]^{-}$anions have broader, more diffuse peaks consistent with the presence of the larger, and conformationally more flexible anion.

Interestingly, the presence of the [OTf] ${ }^{-}$anion leads to shortening of the cation-phenol first peak correlation by ca. $0.2 \AA$ indicating stronger interactions.

\section{3 pRDFs}

It is clear that anion-cation ordering is present in all four mixtures, consistent with previous examination of high concentration organic salt/solute systems where concentric shell-like structures are observed. $\frac{26.28}{26}$

Atom centred partial radial distribution functions (pRDFs) are shown in Figure 5. Many exhibit a double 

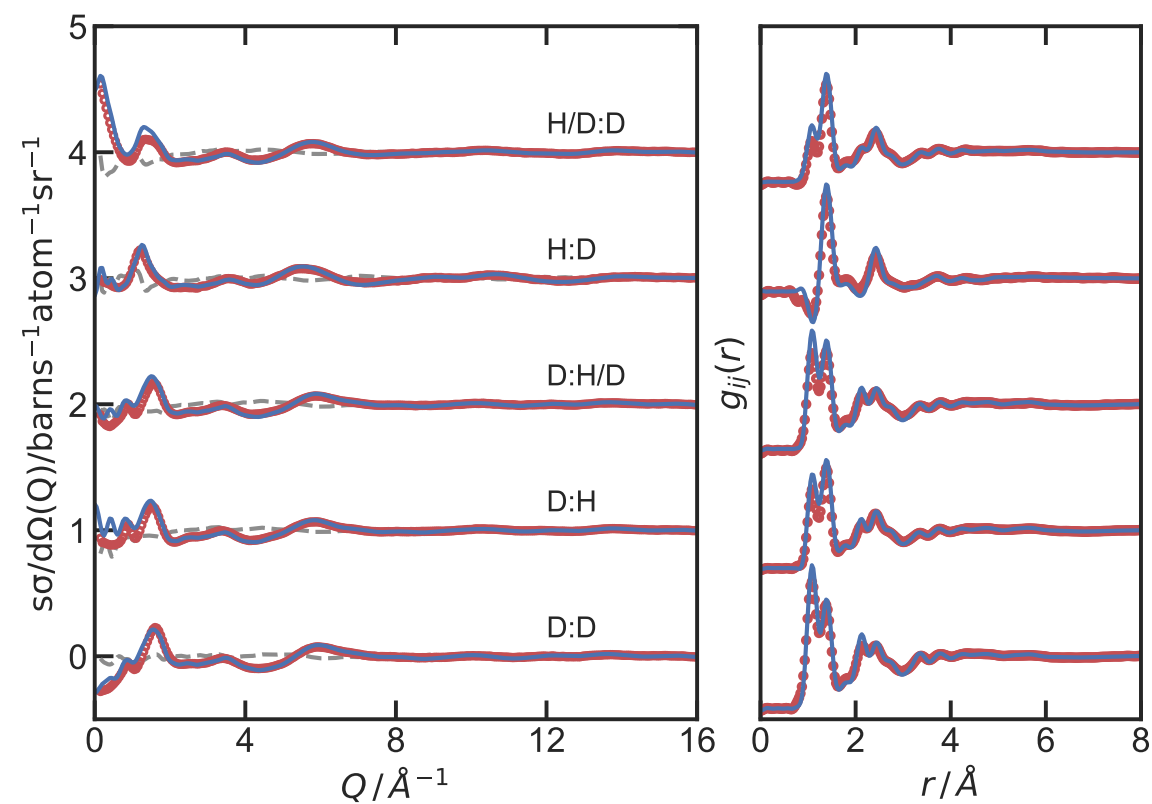

Fig. 3 Comparison of the structure factors (left) and transformations to real space (right) for the experimental (symbols) and EPSR modeled (solid) data for the isotopically labelled 2:1 [Me-3-Pic][OTf]:phenol liquids. Residual differences between the experimental and simulated data are shown by the dashed lines. The curves have been shifted for clarity and are labelled with the isotopic composition of the IL:phenol components. The corresponding data for [Me-3-Pic][NTf $\left.{ }_{2}\right]$, $[\mathrm{Me}-\mathrm{Py}][\mathrm{OTf}]$, and $[\mathrm{Me}-\mathrm{Py}]\left[\mathrm{NTf}_{2}\right]$ can be found in ESI.

peak arrangement at short range. The NR1-F interaction shows a pre-peak arrangement at $\sim 4.6 \AA$ but in [Me-Py] $\left[\mathrm{NTf}_{2}\right]$ eutectic mixtures, this prepeak becomes the primary peak at $5 \AA$ with a secondary peak at $\sim 6$ $\AA$ comparable with the main peak in the other systems.

NR1-O interactions are shorter range than those of the NR1-F in all systems studied consistent with the concept that the anion charge is localised over the $-\mathrm{SO}_{3}$ fragment. The NR1-O interactions also exhibit secondary peaks at $5 \AA$ in $[\mathrm{Me}-\mathrm{Py}]\left[\mathrm{NTf}_{2}\right]$ and $\sim 5.5-5.7 \AA$ in the other systems.

pRDFs including the OP and $\mathrm{O}$ sites, indicative of hydrogen-bond formation show clearly defined secondary peak strucutre in the mixtures containing [OTf] ${ }^{-}$anions. In contrast, in the two mixtures containing $\left[\mathrm{NTf}_{2}\right]^{-}$anions, only a broad correlation with no defined structure is present and this indicates that anionphenol interactions are more structured in the [OTf] ${ }^{-}$containing systems. For [Me-3-Pic][OTf], the second peak is at $4.5 \AA$ and $5 \AA$ for the OP-OP and OP-O interactions respectively, in [Me-Py][OTf] the OP-OP

\begin{tabular}{lcccc}
\hline \multirow{2}{*}{ RDF } & \multicolumn{3}{c}{ Peak Position $(\AA)$} \\
[Me-3-Pic][OTf] & {$\left[\right.$ Me-3-Pic] $\left[\mathrm{NTf}_{2}\right]$} & {$[\mathrm{Me}-\mathrm{Py}][\mathrm{OTf}]$} & {$[\mathrm{Me}-\mathrm{Py}]\left[\mathrm{NTf}{ }_{2}\right]$} \\
\hline Cation-cation & 6.84 & 7.88 & 5.10 & 7.88 \\
Cation-anion & 5.17 & 5.94 & 5.50 & 5.89 \\
Cation-phenol & 5.44 & 5.65 & 6.51 & 5.72 \\
Anion-anion & 6.68 & 8.19 & 5.69 & 8.36 \\
Anion-phenol & 5.60 & 6.57 & 5.50 & 6.50 \\
Phenol-phenol & 5.90 & 5.91 & 5.31 \\
\hline
\end{tabular}

Table 1 Position of the first peak in the centre of mass (COM) radial distribution functions for [Me-3-Pic][OTf], [Me-3$\mathrm{Pic}]\left[\mathrm{NTf}_{2}\right]$, [Me-Py][OTf], and [Me-Py][NTf $\left.{ }_{2}\right]$ 

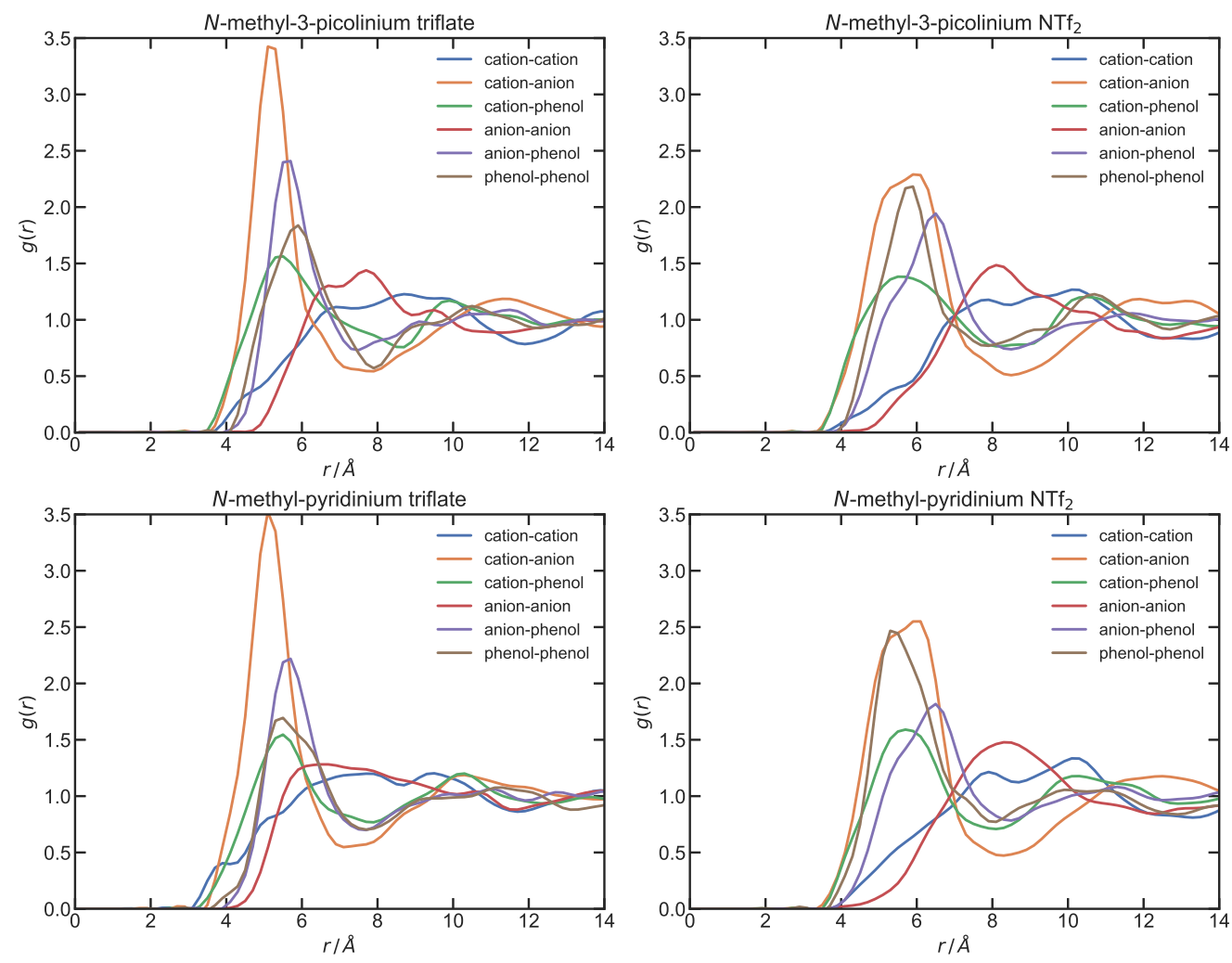

Fig. 4 Centre of mass RDFs for [Me-3-Pic][OTf] (top left), [Me-3-Pic][NTf ${ }_{2}$ ] (top right), [Me-Py][OTf] (bottom left) and $[\mathrm{Me}-\mathrm{Py}]\left[\mathrm{NTf}_{2}\right]$ (bottom right). Centre of mass is defined as the centre of the aromatic ring for cations and phenol molecules, the $\mathrm{C}-\mathrm{S}$ bond in $[\mathrm{OTf}]^{-}$, and the $\mathrm{S}-\mathrm{N}-\mathrm{S}$ backbone for $\left[\mathrm{NTf}_{2}\right]^{-}$anions.

interaction contracts to 3.76 but the OP-O interaction second peak remains at $5 \AA$. For $\left[\mathrm{NTf}_{2}\right]^{-}$mixtures, beyond the primary peak for OP-OP there is a broad distribution with small peaks at 5.7 and $6.9 \AA$ for [Me-3-Pic] $\left[\mathrm{NTf}_{2}\right]$, and 4.6 and $7.4 \AA$ for [Me-Py] $\left[\mathrm{NTf}_{2}\right]$.

Table 2 shows the positions of the primary correlation peaks in the atom-atom partial RDFs and integrated coordination numbers to first minima in the mixtures studied.

Cation pRDFs indicate that NR1-CR4 interactions are stronger than NR1-NR1 interactions in all four systems but the difference is larger for $[\mathrm{Me}-3-\mathrm{Pic}]^{+}$ionic liquid:phenol mixtures due to charge repulsion. Addition of the ring-methyl group causes a significant increase in NR1-CR4 interaction strength for picolinium ILs due to increased ring electronegativity.

\subsection{Spatial density functions}

Plots of the spatial density functions (SDFs) of cations, anions, and phenol centred around either the cation, anion, or phenol for each of the ionic liquid:phenol mixtures derived from the EPSR models are shown in Figure 6 .

For the four cation centred SDFs, anions and phenol molecules are present in the first shell with cations associated at greater distances from the reference cations centre, consistent with the COM RDFs. In each case, phenol molecules are found associated over the faces of the cation's heterocyclic ring with little obvious variation between the four systems. Anions are associated with the plane of the cation ring, showing the largest probability density is association with the charge bearing $(\mathrm{CH})_{2}-\mathrm{N}-\mathrm{CH}_{3}$ region of the cations. In the two systems with $[\mathrm{Me}-\mathrm{Py}]^{+}$cations, anions also show correlation to the $\mathrm{CR} 3-\mathrm{H}$ sites on the pyridinium ring, generating four points of association, whereas with the changes in cation symmetry in the $[\mathrm{Me}-3-\mathrm{Pic}]^{+}$ 


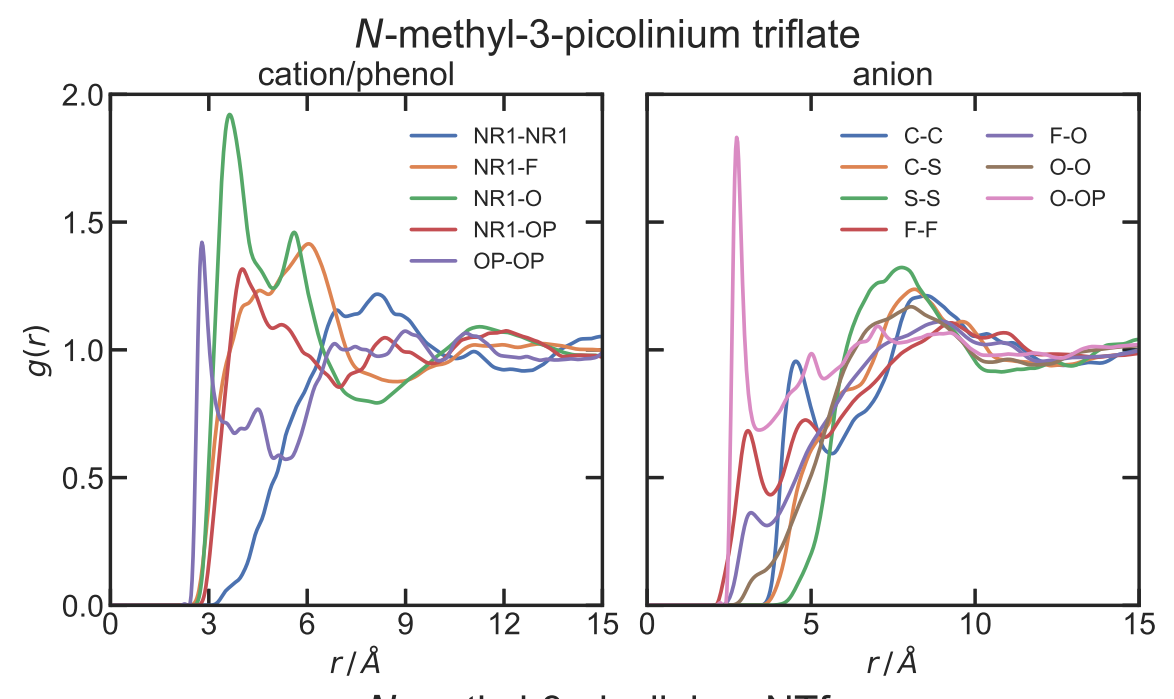

$\mathrm{N}$-methyl-3-picolinium $\mathrm{NTf}_{2}$
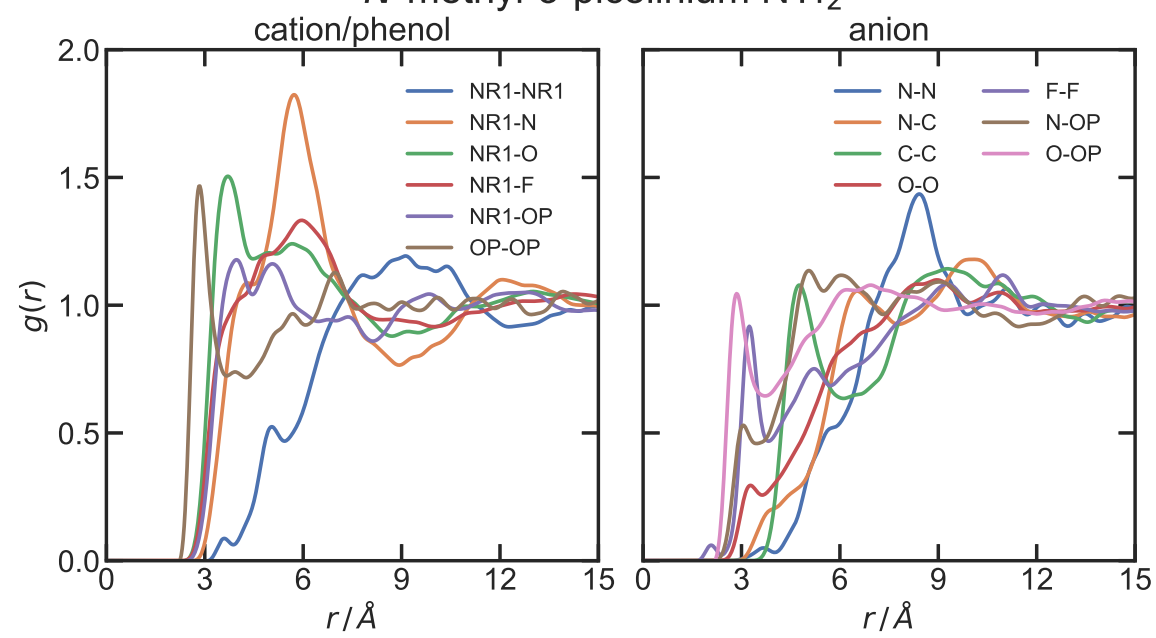

Fig. 5 Atom-centred pRDFs for [Me-3-Pic][OTf] and [Me-3-Pic][NTf $\left.{ }_{2}\right]$. Those for [Me-Py][OTf] and [Me-Py][NTf $\left.{ }_{2}\right]$ can be found in ESI. ${ }^{\dagger}$

systems, there is a shift towards greater correlation to the CR4-H site which is consistent with the increased positive charge on the CR4-H and loss of one CR3-H site to the methyl-substituent.

Within the second shell cation-cation correlations there is a pronounced anion effect on the distribution. With [OTf $]^{-}$, distinct correlation sites within the second shell are evident and extend along the three principle axes symmetrically bisecting the $[\mathrm{Me}-\mathrm{Py}]^{+}$cation. This is most evident for the [Me-Py][OTf]:phenol system and is indicative of relatively high long-range structural correlations. In contrast, the mixtures containing $\left[\mathrm{NTf}_{2}\right]^{-}$anions show cation-cation SDFs with a broad, more diffuse band.

The SDFs showing association of components around the anions are generally diffuse and difficult to interpret other than confirming that both cations and phenol molecules are present in the first coordination shell.

SDFs around phenols show similar patterns for all four mixtures, with well defined interaction sites evident. Cations and phenol molecules association in the first correlation shell above and below the phenol ring, with the cation correlation sites offset slightly in the direction of the phenol hydroxyl group. In contrast, anion density is located around the plane of the phenol ring in four sites bridging HPO/HP2 and HP3/HP4 atomic positions on the $\mathrm{O}-\mathrm{H}$ and ring $\mathrm{C}-\mathrm{H}$ sites. 
Table 2 Coordination numbers calculated for the principle partial RDFs shown in Figure 5 for [Me-3-Pic][OTf], [Me-3$\mathrm{Pic}]\left[\mathrm{NTf}_{2}\right.$ ], [Me-Py][OTf], and [Me-Py][NTf ${ }_{2}$. Mean coordination numbers $N_{\text {coord }}$ were determined to the first minima $\left(r_{\text {min }}\right)$ after the primary correlation peak $\left(r_{\max }\right)$ in the pRDF. $r_{\max }$ and $r_{\text {min }}$ in $\AA$.

\begin{tabular}{|c|c|c|c|c|c|c|c|c|}
\hline \multirow[t]{2}{*}{ pRDF } & \multicolumn{2}{|c|}{ [Me-3-Pic][OTf] } & \multicolumn{2}{|c|}{$[\mathrm{Me}-3$-Pic $]\left[\mathrm{NTf}_{2}\right]$} & \multicolumn{2}{|c|}{ [Me-Py][OTf] } & \multicolumn{2}{|c|}{$[\mathrm{Me}-\mathrm{Py}]\left[\mathrm{NTf}_{2}\right]$} \\
\hline & $r_{\max }\left(r_{\min }\right)$ & $N_{\text {coord }}$ & $r_{\max }\left(r_{\min }\right)$ & $N_{\text {coord }}$ & $r_{\max }\left(r_{\min }\right)$ & $N_{\text {coord }}$ & $r_{\max }\left(r_{\min }\right)$ & $N_{\text {coord }}$ \\
\hline NR1-NR1 & $6.9(8)$ & $5.6 \pm 1.4$ & $7.9(8)$ & $4.0 \pm 1.3$ & $6.8(8)$ & $5.9 \pm 1.3$ & $6.7(8)$ & $3.7 \pm 1.2$ \\
\hline NR1-F & $6.1(8.3)$ & $20 \pm 3.2$ & $6.0(8.3)$ & $31 \pm 4.7$ & $6.0(8.3)$ & $20 \pm 3.4$ & $5.0(8.3)$ & $28 \pm 5.6$ \\
\hline NR1-O & $3.7(5.1)$ & $5.0 \pm 1.6$ & $3.7(5.1)$ & $5.1 \pm 1.6$ & $3.6(5.1)$ & $5.4 \pm 1.7$ & $3.6(5.1)$ & $4.1 \pm 1.7$ \\
\hline NR1-CR4 & $4.7(7)$ & $3.4 \pm 1.2$ & $4.8(7)$ & $2.5 \pm 1.0$ & $6.1(7)$ & $3.8 \pm 1.3$ & $6.4(7)$ & $2.5 \pm 1.0$ \\
\hline NR1-CL & $4.9(5.2)$ & $1.7 \pm 0.7$ & $4.9(5.2)$ & $1.3 \pm 0.5$ & - & & - & \\
\hline NR1-CP4 & $4.7(6.5)$ & $2.7 \pm 1.0$ & $5.0(6.5)$ & $2.0 \pm 0.9$ & $4.8(6.5)$ & $2.8 \pm 1.1$ & $4.7(6.5)$ & $1.0 \pm 1.0$ \\
\hline NR1-OP & $4.1(5.1)$ & $1.2 \pm 0.8$ & $4.0(5.1)$ & $1.0 \pm 0.7$ & $3.6(5.1)$ & $1.1 \pm 0.8$ & $3.9(5.1)$ & $0.4 \pm 0.6$ \\
\hline CR4-CR4 & $3.6(6)$ & $2.2 \pm 0.9$ & $4.0(6)$ & $1.8 \pm 0.8$ & $4.8(6)$ & $2.5 \pm 1.0$ & $4.0(6)$ & $1.9 \pm 0.8$ \\
\hline $\mathrm{C}-\mathrm{C}$ & $4.6(6.15)$ & $2.3 \pm 0.8$ & $4.7(6.15)$ & $3.8 \pm 1.1$ & $4.8(6.15)$ & $2.5 \pm 1.0$ & $5.0(6.15)$ & $4.2 \pm 1.3$ \\
\hline $\mathrm{C}-\mathrm{S}$ & $8.2(5.6)$ & $1.6 \pm 0.6$ & $5.2(5.6)$ & $2.7 \pm 0.8$ & $8.1(5.6)$ & $1.7 \pm 0.7$ & $5.5(5.6)$ & $2.9 \pm 0.9$ \\
\hline$S-S$ & $7.8(10.3)$ & $12 \pm 1.5$ & $8.3(10.3)$ & $19 \pm 2.5$ & $6.8(10.3)$ & $13 \pm 1.8$ & $8.2(10.3)$ & $17 \pm 2.7$ \\
\hline OP-OP & $2.8(3.5)$ & $1.1 \pm 0.4$ & $2.8(3.5)$ & $1.2 \pm 0.4$ & $2.8(3.5)$ & $1.2 \pm 0.4$ & $2.9(3.5)$ & $1.1 \pm 0.3$ \\
\hline OP-CP4 & $3.6(6)$ & $1.9 \pm 1.0$ & $3.6(6)$ & $1.8 \pm 0.8$ & $3.5(6)$ & $2.0 \pm 1.0$ & $4.2(6)$ & $1.8 \pm 0.8$ \\
\hline СР4-CP4 & $5.0(7)$ & $2.7 \pm 1.2$ & $5.1(7)$ & $2.5 \pm 1.0$ & $4.1(7)$ & $2.8 \pm 1.1$ & $4.1(7)$ & $2.5 \pm 1.1$ \\
\hline NR1-N & - & - & $5.7(8.9)$ & $6.0 \pm 1.0$ & - & - & $5.7(8.9)$ & $5.9 \pm 1.2$ \\
\hline $\mathrm{N}-\mathrm{N}$ & - & - & $5.6(6.2)$ & $1.5 \pm 0.6$ & - & - & $8.6(6.2)$ & $1.5 \pm 0.6$ \\
\hline $\mathrm{N}-\mathrm{C}$ & - & - & $3.1(3.6)$ & $0.1 \pm 0.3$ & - & - & $6.7(3.6)$ & $2.0 \pm 0.1$ \\
\hline
\end{tabular}

\subsection{Hydrogen Bonding}

A key part to understanding how the ILs here interact and solvate phenol depends on the magnitude and form of the anion-phenol hydrogen bonding interactions ${ }^{19}$ as the changes in anion have a profound impact on the extraction efficiency as shown in Fig. 2 .

Using the definition that a hydrogen bond of the form $\mathrm{X}-\mathrm{H} \cdots \mathrm{Z}$ is generated from the interaction of an $\mathrm{X}-\mathrm{H}$ hydrogen with an electronegative centre, $\mathrm{Z}$, with a maximum $\mathrm{H} \cdots \mathrm{Z}$ distance of $2.5 \AA$, a maximum $\mathrm{X} \cdots \mathrm{Z}$ distance of $3.2 \AA$ and $\mathrm{X}-\mathrm{H} \cdots \mathrm{Z}$ angle of $>135^{\circ}, \underline{2930}$ the first peaks in the hydroxyl-containing pRDFs in Fig. 5 (such as OP... O and OP... OP) that have a peak with $r_{\text {max }} c a . \sim 2.8 \AA$ and a minima at $3.2 \AA$ are hydrogen bonding.

From Table 3 it can be seen that only HPO $\cdots$ OP, and HPO $\cdots$ O interactions represent medium to strong hydrogen bonds $\left(r_{\max } \ll 2.5\right)$. The total number of hydrogen bonds per phenol molecule remains relatively consistent across the four IL:phenol systems, however, there is a small increase in the coordination number for the HPO $\cdots \mathrm{O}$ interactions in the mixtures containing [OTf] ${ }^{-}$compared to $\left[\mathrm{NTf}_{2}\right]^{-}$. While the HPO $\cdots \mathrm{OP}$ hydrogen bonds are stronger than HPO $\cdots$ O hydrogen bonds, HPO $\cdots$ OP hydrogen bonds are more probable. $\mathrm{OP}-\mathrm{HPO} \cdots \mathrm{X}$ angles (Figure $\mathrm{S}^{\dagger}$ ) show that hydrogen bonds to oxygen species (OP and $\mathrm{O}$ ) are more linear (stronger) than those to fluorine atoms (F). OP-HPO $\cdots$ O hydrogen bonds are more linear than OP-HPO $\cdots$ OP hydrogen bonds for all four mixtures indicating that they are stronger and a driving force for solvation.

Hydrogen bonding in the four IL:phenol mixtures can be broken down into two categories, homo- and hetero-hydrogen bonds, the former involving only molecules of one type (in this case phenol), the latter all species in the system capable of forming hydrogen bonds. ${ }^{30}$ [Me-3-Pic][OTf] has $1.96 \pm 1$, of which $1.05 \pm 0.22$ (53.6 \%) are homo-hydrogen bonds, [Me-3-Pic] [NTf 2 ] has $1.96 \pm 1.14$, of which $1.09 \pm 0.29$ (55.6 $\%)$ are homo-hydrogen bonds. [Me-Py][OTf] has 1.98 \pm 1.14 , of which $1.08 \pm 0.28$ (54.5 \%) are homohydrogen bonds, [Me-Py] $\left[\mathrm{NTf}_{2}\right]$ has $1.85 \pm 1.1$, of which $1.03 \pm 0.18$ (55.7\%) are homo-hydrogen bonds. The distribution between homo- and hetero-hydrogen bonds remain the same for $\left[\mathrm{NTf}_{2}\right]^{-}$showing inde- 
Table 3 Hydrogen bonding interactions for HPO ...X distributions in the IL:phenol mixtures. Coordination numbers within $2.5 \AA$ and the primary correlation peak $\left(r_{\max }\right)$ in the pRDF of the HPO $\ldots$ X interactions across all IL:phenol mixtures. Distances are given in $\AA$

\begin{tabular}{|c|c|c|c|c|c|c|c|c|}
\hline \multirow[t]{2}{*}{ НPO $\cdots$} & \multicolumn{2}{|c|}{ [Me-3-Pic][OTf] } & \multicolumn{2}{|c|}{$[\mathrm{Me}-3-\mathrm{Pic}]\left[\mathrm{NTf}_{2}\right]$} & \multicolumn{2}{|c|}{ [Me-Py][OTf] } & \multicolumn{2}{|c|}{$[\mathrm{Me}-\mathrm{Py}]\left[\mathrm{NTf}_{2}\right]$} \\
\hline & $r_{\max }$ & $N_{\text {coord }}$ & $r_{\max }$ & $N_{\text {coord }}$ & $r_{\max }$ & $N_{\text {coord }}$ & $r_{\max }$ & $N_{\text {coord }}$ \\
\hline$\overline{\mathrm{OP}}$ & 1.92 & $1.05 \pm 0.22$ & 1.89 & $1.09 \pm 0.29$ & 1.92 & $1.08 \pm 0.28$ & 1.95 & $1.03 \pm 0.18$ \\
\hline $\mathrm{O}$ & 1.78 & $0.81 \pm 0.46$ & 1.81 & $0.74 \pm 0.49$ & 1.79 & $0.77 \pm 0.47$ & 1.79 & $0.68 \pm 0.53$ \\
\hline $\mathrm{F}$ & 2.04 & $0.10 \pm 0.31$ & 2.10 & $0.13 \pm 0.36$ & 2.31 & $0.13 \pm 0.39$ & 1.91 & $0.17 \pm 0.42$ \\
\hline
\end{tabular}

pendence from cation electron density. Higher cation electron density increases the proportion of heterohydrogen bonds, corroborating the observation of closer cation-phenol association, and a generally more homogeneous system. Cation electron density greatly increases hydrogen bonding in $\left[\mathrm{NTf}_{2}\right]^{-}$mixtures but has less of an effect on [OTf] ${ }^{-}$systems because of the improved cation-phenol interactions improving phenol inclusion towards a more homogeneous mixture.

\section{Conclusion}

Aromatic cation-ionic liquids are shown to be good literature comparable extractants for phenol remediation from model oils. The [OTf] ${ }^{-}$anion showed better efficiency than $\left[\mathrm{NTf}_{2}\right]^{-}$, comparable to benchmarked halide salts. Assumptions about structural interactions were confirmed using small angle neutron diffraction.

Structure correlations in four eutectic-forming pyridinium salt/phenol mixtures with [Me-Py] $\left[\mathrm{NTf}_{2}\right]$, [MePy][OTf], [Me-3-Pic][NTf ${ }_{2}$ ] and [Me-3-Pic][OTf] have been studied using neutron scattering and EPSR modeling of the experimental data. Strong first shell cation-phenol and phenol-anion correlations were observed as dominant structural motifs alongside ionic liquid lattice forming anion-cation first shell correlations.

The overall structure and bulk correlations between the components does not change significantly on substituting either the cation $\left([\mathrm{Me}-\mathrm{Py}]^{+}\right.$for $[\mathrm{Me}-3-\mathrm{Pic}]^{+}$) or the anion $\left(\left[\mathrm{NTf}_{2}\right]^{-}\right.$for $\left.[\mathrm{OTf}]^{-}\right)$, although the first shell cation-phenol and phenol-anion, and second shell cation-cation correlations become sharper and more defined with the smaller, and more strongly hydrogen-bond accepting [OTf $]^{-}$anion is used.

Small increases in the phenol-anion hydrogen bonding coordination numbers in the [OTf] ${ }^{-}$systems also appear to result in synergistic increases in the strength of cation-phenol association, evidenced in the shorter length of the first peak in the COM RDF, giving rise to the more structured liquid.

These combinatorial effects result in the observed enhancement of phenol extraction from hydrocarbons through eutecitc formation. Small modifications to the cation, increasing electron density by changing from $[\mathrm{Me}-\mathrm{Py}]^{+}$to $[\mathrm{Me}-3-\mathrm{Pic}]^{+}$lead to commensurately small improvements in extraction efficiency.

\section{Conflicts of interest}

There are no conflicts to declare.

\section{Acknowledgements}

The authors acknowledge funding and support from the Department for Employment and Learning, Northern Ireland (to AHT), the Science and Technology Facilities Research Council (STFC) for beam-time on SANDALS (ISIS experiment RB1410403), and Dr Samantha K. Callear (ISIS, Rutherford Appleton Laboratory) for support during data collection. Thaise Pereira for initial work on the project. AHT would also like to thank the Ateneo de Manila University for the support through the Early Career Support Grant.

Data files are freely available from https://doi.org/10.5286/ISIS.E.RB1510233 in accordance with ISIS data management policy.

\section{Notes and references}

1 F. S. vom Saal and J. Myers, JAMA, 2008, 300, 1353-1355. 
2 T. Deblonde, C. Cossu-Leguille and P. Hartemann, Int. J. Hyg. Environ. Health, 2011, 214, 442-448.

3 H. H. Schobert and C. Song, Fuel, 2002, 81, 15-32.

4 C. Yang, Y. Qian, L. Zhang and J. Feng, Chem. Eng. J., 2006, 117, 179-185.

5 M. M. Weber, Phenolic Resins A Century Prog., Springer-Verlag, 2010, pp. 9-23.

6 G. Busca, S. Berardinelli, C. Resini and L. Arrighi, J. Hazard. Mater., 2008, 160, 265-88.

7 D. C. Greminger, G. P. Burns, S. Lynn, D. N. Hanson and C. J. King, Ind. Eng. Chem. Process Des. Dev., 1982, 21, 51-54.

8 J. P. Hallett and T. Welton, Chem. Rev., 2011, 111, 3508-3576.

9 J. Estager, J. D. Holbrey and M. Swadźba-Kwaśny, Chem. Soc. Rev., 2014, 43, 847-886.

10 S. T. M. Vidal, M. J. Neiva Correia, M. M. Marques, M. R. Ismael and M. T. Angelino Reis, Sep. Sci. Technol., 2005, 39, 2155-2169.

11 K. S. Khachatryan, S. V. Smirnova, I. I. Torocheshnikova, N. V. Shvedene, A. a. Formanovsky and I. V. Pletnev, Anal. Bioanal. Chem., 2005, 381, 464-70.

12 Y. Fan, Y. Li, X. Dong, G. Hu, S. Hua, J. Miao and D. Zhou, Ind. Eng. Chem. Res., 2014, 53, 20024-20031.

13 H. Meng, C. T. Ge, N. N. Ren, W. Y. Ma, Y. Z. Lu and C. X. Li, Ind. Eng. Chem. Res., 2014, 53, 355-362.

14 T. Jiao, C. Li, X. Zhuang, S. Cao, H. Chen and S. Zhang, Chem. Eng. J., 2015, 266, 148-155.

15 W. Guo, Y. Hou, S. Ren, S. Tian, W. Wu, S. Ren, S. Tian and K. N. Marsh, Green Chem., 2013, 15, 226-229.

16 C. Yao, Y. Hou, S. Ren, W. Wu, K. Zhang, Y. Ji and H. Liu, Chem. Eng. J., 2017, 326, 620-626.

17 T. Jiao, X. Qin, H. Zhang, W. Zhang, Y. Zhang and P. Liang, Chem. Eng. Res. Des., 2019, 145, 112-121.

18 J. R. Harjani, R. D. Singer, M. T. Garcia and P. J. Scammells, Green Chem., 2009, 11, 83.

19 A. H. Turner and J. D. Holbrey, J. Solution Chem., 2015, 44, 621-633.

20 A. K. Soper, GudrunN and GudrunX: Programs for correcting raw neutron and X-ray diffraction data to differential scattering cross section, Rutherford appleton laboratory technical report, 2011.

21 A. K. Soper, Chem. Phys., 1996, 202, 295-306.

22 A. K. Soper, Mol. Phys., 2001, 99, 1503-1516.

23 Y. Ji, Y. Hou, S. Ren, C. Yao and W. Wu, Fuel Process. Technol., 2018, 171, 183-191.

24 K. Pang, Y. Hou, W. Wu, W. Guo, W. Peng and K. N. Marsh, Green Chem., 2012, 14, 2398.

25 J. D. Holbrey, I. López-Martin, G. Rothenberg, K. R. Seddon, G. Silvero and X. Zheng, Green Chem., 2008, 10, 87.

26 C. Hardacre, J. D. Holbrey, C. L. Mullan, M. Nieuwenhuyzen, T. G. A. Youngs, D. T. Bowron and S. J. Teat, Phys. Chem. Chem. Phys., 2010, 12, 1842-53.

27 T. G. A. Youngs, J. D. Holbrey, C. L. Mullan, S. E. Norman, M. C. Lagunas, C. D’Agostino, M. D. Mantle, L. F. Gladden, D. T. Bowron and C. Hardacre, Chem. Sci., 2011, 2, 1594.

28 S. E. Norman, A. H. Turner, J. D. Holbrey and T. G. A. Youngs, ChemPhysChem, 2016, 17, 3923-3931.

29 J. Padró, L. Saiz and E. Guàrdia, J. Mol. Struct., 1997, 416, 243-248.

30 A. H. Turner and J. D. Holbrey, Phys. Chem. Chem. Phys., 2019, 21, 21782-21789. 

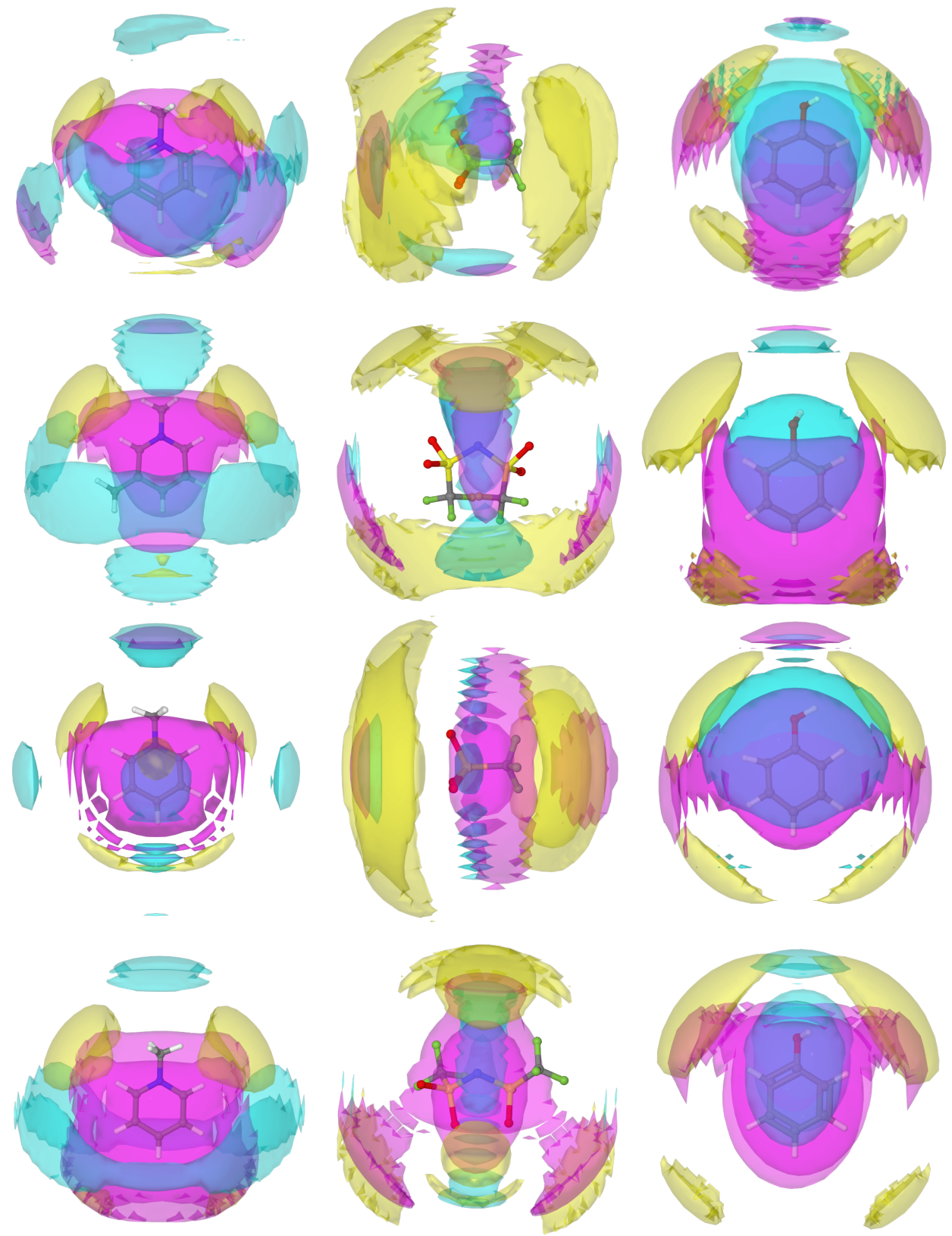

Fig. 6 Plots of the spatial density functions (SDFs) in 3 dimensions for [Me-3-Pic][OTf] (top), [Me-3-Pic][NTf $\left.{ }_{2}\right]$ (middletop), [Me-Py][OTf] (middle-bottom), and [Me-Py][NTf 2 (bottom). Left is around a central cation, centre is around central anion, and right is around a central phenol molecule. Cation (cyan), anion (yellow), and phenol (purple). 